\title{
Limb-girdle muscular dystrophy in Brazilian children: clinical, histological and molecular characterization
}

\author{
Distrofia muscular de cinturas em crianças brasileiras: caracterização clínica, histologia e \\ molecular
}

Marco A. Veloso Albuquerque

Resumo da Dissertação de Doutorado apresentada ao Departamento de Doenças Neuromusculares, Faculdade de Medicina da Universidade de São Paulo. Área de Doenças Neuromusculares. São Paulo SP.

Correspondence: Marco A. Veloso Albuquerque; Rua Dr Enéas de Aguiar 255; 01246-903 São Paulo SP, Brasil; E-mail: marcoveloso@yahoo.com

Conflict of interest: There is no conflict of interest to declare.

Orientadora: Umbertina Conti Reed.

Received 29 January 2014; Received in final form 18 March 2014; Accepted 7 April 2014

\begin{abstract}
Limb-girdle muscular dystrophies (LGMD) are a heterogeneous group of genetic muscular dystrophies, involving 16 autosomal recessive subtypes and eight autosomal dominant subtypes. Autosomal recessive dystrophy is far more common than autosomal dominant dystrophy, particularly in children. The clinical course in this group is characterized by progressive proximal weakness, initially in pelvic and after in shoulder-girdle musculature, varying from very mild to severe degree. Significant overlap of clinical phenotypes, with genetic and clinical heterogeneity, constitutes the rule for this group of diseases. Muscle biopsies are useful for histopathologic and immunolabeling studies, and DNA analysis is the gold standard to establish the specific form of muscular dystrophy. Objectives: The aim of this study was to characterize the clinical, histological and molecular aspects in children with LGMD who attend a big public neuromuscular centre in our country to determine the frequency of different forms. Method: Thirty seven patients were classified as LGMD and included in this analysis. The study period extended from 2009-2012. The female to male ratio was 3:1. The age of onset ranged from two to 13 years, mean 7,5 years. Onset in the first decade was seen in $90 \%$. Results: The initial clinical signs included: frequent falls (22 cases), difficulty in climbing stairs ( 13 cases), walk on tip toes (2 cases), difficulty in rising from the floor (2 cases) and difficulty on walking (1 case). The serum CK levels were high in all cases. Among the 37 patients, 15 (40,5\%) were classified as sarcoglycanopathies (LGMD2C-F), five (13,5\%) as dysferlinopathy (LGMD2B), five (13,5\%) as calpainopathy (LGMD2A). Mutations in LMNA gene (LGMD1B), FKRP gene (LGMDI) and caveolin gene (LGMD 1C) were identified in two (5,5\%), two (5,5\%) and one patient (2,5\%), respectively. In seven of 37 cases (19\%) it was impossible to determine specific diagnosis. Calf hypertrophy, scapular winging and scoliosis were the most characteristic signs in sarcoglycanopathies. In LGMD2I calf hypertrophy is also observed. Atrophy of posterior compartment of thighs is frequent in children with LGMD2B and could suggest the diagnosis. In LGMD2A winging of scapulae and contractures in Achilles tendons were important findings. Muscle biopsy showed a dystrophic pattern in all cases, more intense in sarcoglycanopathies and LGMD2I. Differently from adult's patients, inflammation changes in dysferlinopaties were uncommon. Lobuled fibers were characteristic changes in calpainopathies in children. Conclusions: A definitive diagnosis among various subtypes of LGMD in children is challenging. Our series was a large study on LGMD in Brazilian children and showed high frequency of sarcoglycanopathies followed by LGMD2A, LGMD2B, LGMD2I, LGMD1B and LGMD1C.
\end{abstract}

Keywords: Limb-girdle muscular dystrophy, child, muscular dystrophy, biopsy, pathology. 